\title{
TRUCOS EN VEJIGA
}

\author{
José Vicente Rodríguez
}

Fundación Puigvert Barcelona. Barcelona. España.

\section{ÍN DICE/ RESUMEN}

1. Trucos en la contracción de adductores.

J. Vicente Rodríguez.

2. Trucos en perforación vesical.

J. Vicente Rodríguez.

3. Trucos en litotricia vesical.

J. Vicente Rodríguez.

Palabras clave: Trucos en vejiga. Trucos en la contracción de adductores. Perforación vesical. Litotricia vesical.

\section{TRUCOS EN LA CONTRACCÓN DEADDUCTORES}

J. Vicente Rodríguez.

El nervio obturador, que recorre externamente la pared infero-lateral de la vejiga, (ver figura) puede ser estimulado por la corriente eléctrica, provocando la contracción brusca de los músculos adductores. Como consecuencia aumenta el peligro de perforación vesical e interrumpe la resección en los tumores vesicales situados en la pared lateral. Su incidencia es escasa; en nuestra experiencia del $1.7 \%$ (1)

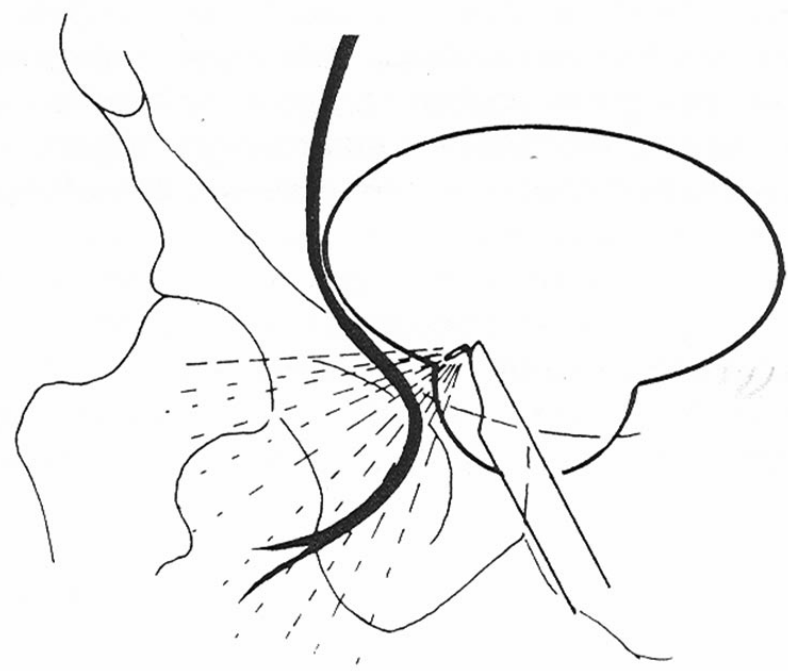

A nte esta situación podemos emplear varios "trucos" que de los más simples a los mas complejos, pueden resolver este problema peroperatorio:

1. Vaciado parcial del líquido vesical (aumenta la distancia entre pared vesical y nervio) y disminución 
del voltaje eléctrico ( se reduce el estímulo al reducir la intensidad de corte). Si no se soluciona la contracción sumar:

2. Cambio de situación del electrodo indiferente, por ejemplo debajo de la pantorrilla de la pierna contralateral (aumentar la distancia entre asa de corte activa y placa / electrodo) y realizar toques intermitentes de coagulación previos al corte (disminución de respuesta estimulante).

3. Si estas medidas no reducen la estimulación eléctrica del nervio obturador, este debe bloquearse mediante la inyección endoscópica de anestésico local en la base tumoral (2) o bien externamente con infiltración anestésica del nervio obturador.

4. Si no se obtiene el resultado previsto y el paciente está sometido a anestesia intra/ extradural, la anestesia general utilizando curarizantes o succinilcolina (lógicamente con respiración asistida), bloquea la placa motora y por consiguiente anula el estímulo nervioso periférico.

5. En caso de disponibilidad, la utilización de energía láser (en nuestra experiencia N d-YA G laser) 0 resector con corriente bipolar, la ausencia de corriente eléctricas entre placa y tumor anulan definitivamente la contracción de nervios adductores, durante la RTU de Tm vesicales.

\section{BIBUOGRAFÍA RECOMENDADA}

1. VICENTE, R.: "Tratamiento Endoscópico". Tumores vesicales superficiales. Ed. Dr. J. Vicente, G. Chechile, J. Salvador. Editorial Acción Médica, 121, 2000.

2. AUGSPURGER, R.; DONAHUE, R.E.: "Prevention of obturator nerve stimulation during transurethral surgery”. J. Urol., 123: 170, 1980.

\section{TRUCOS EN PERFORACIÓN VESICAL}

J. Vicente Rodríguez.

La perforación vesical durante la Resección Transuretral del tumor vesical, puede ser intencionada (en Tm profundos) 0 incidental (contracción de adductores, defecto técnico, etc).
Según localización: extraperitoneal (RTU en Tms de pared lateral o retrotrígono) 0 intraperitoneal (tumor en pared posterior o cúpula). La incidencia global fluctúa entre el 2.5 y $5 \%$, aunque en nuestra experiencia ha sido del $1.3 \%$, de ellas el $80-85 \%$ extraperitoneales.

En la perforación incidental, como accidente peroperatorio, los "trucos" deben orientarse a : como detectarlas y como tratarlas.

- La perforación vesical puede reconocerse como orificio oscuro en el fondo del lecho de resección, pero frecuentemente pasa desapercibida oculta por franjas o sangrado.

Debe sospecharse por la escasa recuperación del líquido intravesical a través de la vaina del resector, asociado a molestia abdominal e intranquilidad del paciente (perforación extraperitoneal) 0 dolor brusco hipogástrico irradiado a hombro derecho, asociado a distensión / palpación abdominal dolorosa (en perforación intraperitoneal).

- Cuando detectamos la perforación debemos reducir el ingreso de líquido irrigante y según la sintomatología, acabar rápidamente o suspender la resección tumoral.

En la perforación extraperitoneal interesa: realizar buena hemostasia (evitar el lavado vesical postoperatorio), colocar sonda uretral que asegure buen drenaje y larga permanencia (6-8 días) bajo protección antibiótica (1). En la perforación intraperitoneal, la mayoría de autores recomienda revisión quirúrgica inmediata (2); nosostros realizamos: punción transperitoneal con aguja / catéter de diálisis peritoneal (tercio infero - lateral del abdomen); con ello conseguimos un excelente drenaje del líquido intravesical extravasado durante unas 10-12 horas, bajo protección antibiótica y conducta expectante.

\section{BIBUOGRAFÍA RECOMENDADA}

1. VICENTE, R.: “Tratamiento endoscópico en Tumores vesicales superficiales". Ed. J. Vicente, G. Chéchile, J. Salvador. Editorial Acción Médica, 121, 2000.

2. MAUEMAYER, W.: "Transurethral bladder surgery in transurethral surgery”. Mauenmayer W.Springverñlag. Berlín: 283. 


\section{TRUCOS ENDOUROLÓGICOS EN UTOTRI- CIA VESICAL}

J. Vicente Rodríguez.

Los cálculos de gran volumen y cuerpos extraños endovesicales, han sido tratados mediante cistolitotomía, extrayéndolos a través de la incisión hipogástrica mediante pinzas de distinto diseño. Los cálculos de menor volumen y/ o dureza y ciertos cuerpos extraños calcificados, son resueltos con litotricia "in situ" a través de instrumentos transuretrales. Posteriormente se ideó la litotricia / extracción utilizando instrumental endoscópico a través del tubo de Amplą hipogástrico (1).

Nosotros hemos utilizado como litotricia endoscópica la electrohidráulica a través de parendoscopio 21 y la neumática, inicialmente, a través de nefroscopio $24 \mathrm{Ch}$. (2). En casos de uretra "justa" o con fin de evitar traumatismo uretral en cálculos vesicales grandes o muy duros (necesidad de extraer y reintroducir el instrumento endoscópico), utilizamos inicialmente litotricia a través de tubo de Amplat.

Durante los últimos años hemos substituido el tubo de Amplatz por el trócar laparoscópico de Hasson. Su técnica ya ha sido descrita por nosotros (3) y se esquematiza en la siguiente Figura:

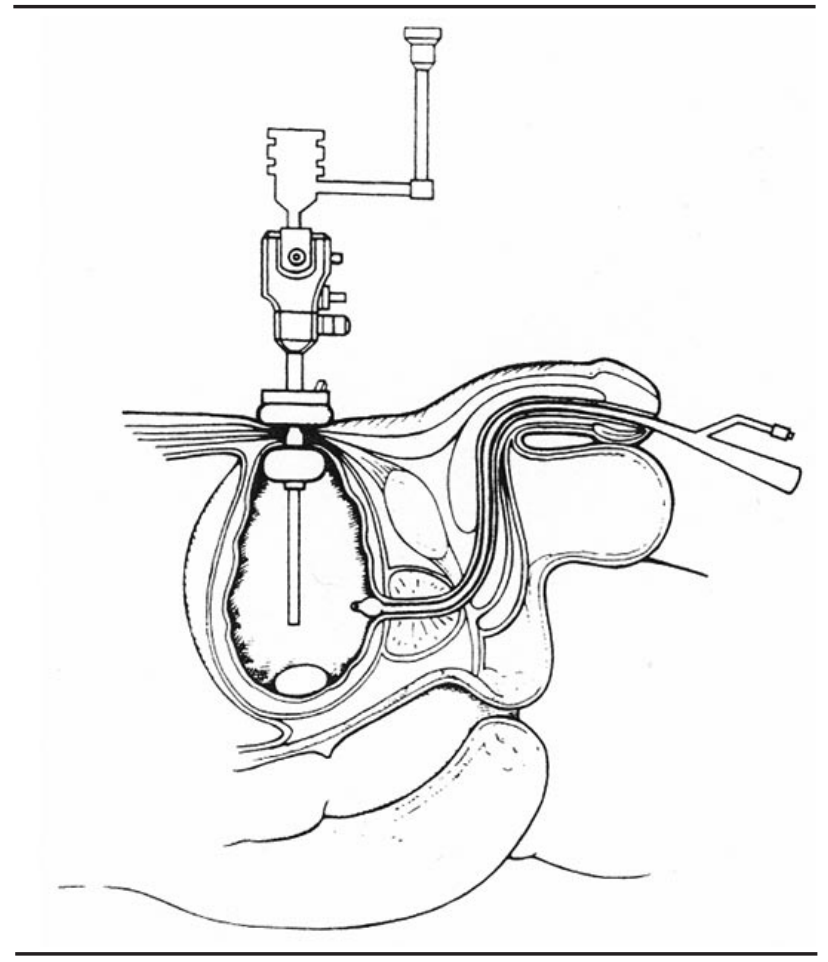

En nuestra experiencia (23 casos) con este "truco técnico" hemos observado las siguientes ventajas:

- Comparado con la cistolitotomía clásica: menor incisión suprapúbica, menor morbilidad, menor estancia hospitalaria.

- Comparado con la litotricia endoscópica transuretral; menor traumatismo uretral, menor tiempo quirúrgico y extracción de fragmentos más grandes.

- Comparado con la utilización del Amplatz suprapúbico: más fácil el crear el tracto percutáneo, evitar cualquier extravasación líquida (el balón del trócar comprime la pared vesical) y facilitar la extracción calculosa dado el sistema valvular estanco y la posibilidad de utilizar pinzas tridentes, etc.

\section{BIBUOGRAFÍA RECOMENDADA}

1. PRESS, S.M.; SMITH, A.D.: "Use of plastic maleable dilators Amplatz system". Controversies in Endourology. Ed. AD. Smith Philadelphia, Saunders, 51, 1995.

2. HERRANDO, C.; LAGUNA, P.; SALVADOR, J. y cols.: "Litotricia endoscópica con lithoclast". Arch. Esp. Urol., 48: 621, 1955.

3. SEGARRA, J.; PALOU, J.; MONTLLEÓ, M. y cols.: "Hassons's laparoscopic trocar in percutaneous bladder stone litotripsy". International Urology and Nephrology, 33: 625, 2001. 